\title{
Assessment of drug therapy problem and associated factors among adult hypertensive patients at Ayder comprehensive specialized hospital, Northern Ethiopia
}

\author{
Asgedom Solomon Weldegebreal, Fekadu Tezeta, Atey Tesfay Mehari, Wubetu Gashaw, \\ Kassa Tesfaye Dessale, Niriayo Yirga Legesse,
}

Clinical Pharmacy Unit, School of Pharmacy, College of Health Sciences, Mekelle University, Ethiopia.

\begin{abstract}
Background: Drug-therapy problems(DTPs) among hypertensive patients can result in patient's morbidity and mortality. The main aim of this study was to assess drug therapy problem and associated factors among <="" span="" style="font-family: hypertensive patients.

Methods: A hospital based cross sectional study was conducted. The data was collected from patients' medical charts and through interview. Drug therapy problem was categorized according to Cipolle methods of DTP classification. Thedata was analyzed using the Statistical Package for the Social Sciences (SPSS), version 21.

Results: A total of 241 patients were studied. The mean number of antihypertensive medications prescribed were $1.41 \pm 0.53$. A total of 357 drug therapy problems(DTPs) were identified. From the patients studied,134(55.6\%) had at least one evidence of drug therapy problem. Non adherence was the most commonly identified drug therapy problem occurred in $(143(59.3 \%))$ patients. Substance use $(\mathrm{AOR}=0.445,95 \% \mathrm{CI}=0.227-0.870, \mathrm{p}=0.018)$ and comorbidity $(\mathrm{AOR}=2.099,95 \% \mathrm{CI}=1.192-3.694$, $\mathrm{p}=0.010)$ werethe predictors of DTP.

Conclusion: More than half of the participants had evidence of onset drug therapy problem. Thus efforts that could boost antihypertensive compliance and minimizes substance use should be adopted to reduce patients's drug therapy problems.

Keywords: assessment, drug, therapy, problem, Ethiopia.

DOI: https://dx.doi.org/10.4314/ahs.v19i3.33

Cite as: Weldegebreal AS, Tezeta F, Mehari AT, Gashaw W, Dessale KT, Legesse NY. Assessment of drug therapy problem and associated factors among adult hypertensive patients at Ayder comprehensive specialized hospital, Northern Ethiopia. Afri Health Sci. 2019;19(3): 2571-2579. https:// dx.doi.org/10.4314/abs.v19i3.33
\end{abstract}

\section{Background}

Hypertension(HTN) is a silent killer disease in both developed and developing countries. It is among the leading risk factors for cardiovascular diseases and which is a major cause of death globally. ${ }^{1,2}$ It is estimated that the

\section{Corresponding author: \\ Asgedom Solomon Weldegebreal, \\ Mekelle University \\ College of Health Science \\ School of Pharmacy \\ Phone number: +251920871964 \\ P. O. Box: 1871 \\ Fax: 251-344-41-66-75/41-66-81 \\ Mekelle, Ethiopia \\ Email: solomon.asgedom@mu.edu.et}

world wide prevalence of hypertension could increase from $26.4 \%$ in 2000 to $29.2 \%$ in $2025 .{ }^{3}$ By $2025,125.5$ million people in sub-Saharan Africa will be expected to be affected by HTN. ${ }^{4}$

The prevalence of hypertension in Ethiopia is escalating because of increase in risk factors like smoking, obesity, harmful use of alcohol and lack of exercise. However, awareness about treatment and control of hypertension is extremely low in Ethiopia. ${ }^{5}$ The intention of prescribing drugs to patients is treatment, prophylaxis or diagnosis of medical conditions; however, these drugs may have negative effects on patients if not used appropriately. ${ }^{6}$ Inadequate treatment of hypertension can lead to congestive heart disease(CHD), acute myocardial infarction(A$\mathrm{MI}$ ), peripheral vascular disease(PVD), stroke, congestive heart failure $(\mathrm{CHF})$ and renal failure. Because of these it is the leading cause of morbidity and mortality among 
non-communicable diseases, and accounts for $13 \%$ of all deaths globally. ${ }^{11,12,13,14}$

Analysis of the global burden of hypertension revealed that over $26 \%$ of the world's adult population had hypertension in 2000 and has shown a rapid increase in prevalence affecting significant numbers of individuals in sub-Saharan Africa. Although there is a shortage of extensive data, available data shows an overall prevalence of $5-20 \%$ in Oromo region. ${ }^{14,15}$ Despite the availability of effective medical therapy, more than half of hypertensive patients on treatment has uncontrolled blood pressure. This is mostly because of drug therapy problems (DTPs). ${ }^{16,17,18,19}$

In Ethiopia the prevalence of DTP ranged from 73.5$80.7 \% .^{20,21}$ The most frequently identified cause for drug therapy problems are drug choice problems, dosing problems and/or drug interactions. ${ }^{18}$ On the other hand, patients usually had drug use problems caused by "drug use process, lack of information, and physiological or patient factor. $^{19}$

The occurrence of DTP among hypertensive patients could prevent or delay patients from achieving desired therapeutic goals. It has been attributed to unnecessary over-prescription of drugs, substantial worsening of diseases, avoidable increases in hospital admission rates, and longer hospital stays leading to a significant medical burden. As a result, it resulted in poor health outcomes, lower quality of life, increased health care costs and erodes public confidence in health systems. ${ }^{12,14}$

Interventions to improve DTPs are needed to overcome the harms imposed by the problem. If such interventions are to be successfully designed, targeted, and cost effective, it is critical to understand the complex reasons for drug therapy problems and to identify those that are modifiable in hypertensive patients. The aim of the study was to assess DTPs and associated factors among adult hypertensive patients in Ayder Comprehensive Specialized Hospital(ACSH), Northern Ethiopia.

\section{Research methods and participants}

A hospital-based cross-sectional study among adult hypertensive patients was conducted at the ambulatory hypertension clinic of ACSH from March to June 2016. ACSH is located in Mekelle City, the capital of Tigray Regional State, which is $783 \mathrm{~km}$ away from the capital of Ethiopia, Addis Ababa. ACSH is the only teaching and referral hospital in the region. The hospital is having 400 beds to serve its patients. It provides general outpatient, inpatient and emergency services for about nine million people in the catchment area of Tigray, Afar and South-eastern parts of Amhara Regional States. ACSH provides general surgery and orthopedic, gynecology \& obstetrics, pediatric and child health in addition to internal medicine, dermatology, psychiatric and dental services to the general public.

There were 2113 registered hypertensive patients at the ambulatory clinic of ACSH. Single proportion formula was used to calculate the minimum sample size needed. Considering 1.96 for the standard normal variable with $5 \%$ level of significance ( $\alpha$ - value), 0.8 prevalence of DTP in Adama, Ethiopia, ${ }^{9} 95 \%$ confidence interval, $5 \%$ margin of error and $10 \%$ contingency, the sample size was calculated to be 241 .

The study was approved by the Institutional Ethical Review Board of College of Health Sciences, Mekelle University. ACSH also give permission the study to be conducted on the hypertensive clinic. Informed written consent was obtained from all patients prior to face to face interview. Patients personal information like name were not recorded to maintain patient's confidentiality. A face-to-face interview using a pretested structured questionnaire was conducted to collect the socio-demographics, clinical characteristics and adherence status of patients to antihypertensive medication(s). Data on comorbidities, antihypertensive medications and a one-year blood pressure(BP) measurements were extracted from medical records of patients using a pretested data abstraction checklist.

All hypertensive patients aged 18 years and above, who had a regular follow-up for at least 12 months at ACSH hypertension clinic and whose medical records contained complete data and who were willing to participate were included in the study. Seriously ill patients who were not able to finish interview and patients with incomplete medical records were excluded from the study. The data were collected by trained clinical nurses working out of ACSH.

To maintain validity of the data collection tool, a structured questionnaire was developed and translated into 
local languages (Amharic and Tigrigna) and back translated to English. The primary outcome of the study was presence of DTP.

\section{Classification of drug therapy problem}

DTP was identified with reference to Joint National committee (JNC-8). Drug therapy problem was categorized according to a Cipollea method of DTP classification. There are seven basic categories of DTPs according to the book. These are: indication, effectiveness, safety and adherence. $^{22}$ The DTPs and their possible causes were identified from the patients' medical records and patients interview.

\section{Variables}

The dependent variable was presence of DTP whereas the independent variables were age, sex, number of drugs, co-morbidity, socio-demographic characteristics, substance use, occupation, number of anti-hypertension medications, life style modification, mode of medication intake i.e. free or pay, duration of hypertension since diagnosis and family history of hypertension.

\section{Operational definitions}

Hypertension was defined as sustained high blood pressure ( $\mathrm{SBP} \geq 140$ or $\mathrm{DBP} \geq 90 \mathrm{mmHg}$ ) or reported regular use of antihypertensive medication(s).Uncontrolled blood pressure was defined as systolic blood pressure of $\geq 140 \mathrm{mmHg}$ and/or diastolic blood pressure of $\geq 90$ mmHg. ${ }^{9}$ Controlled blood pressure was defined as systolic blood pressure of $<140 \mathrm{mmHg}$ and/or diastolicblood pressure of $<90 \mathrm{mmHg}{ }^{9}$ A DTP is defined as any undesirable event experienced by a patient which involves, or is suspected to involve, drug therapy, and that interferes with achieving the desired goals of therapy, which can be identified using JNC-8 guidelines except compliance. ${ }^{23}$ Any deviation from the JNC-8 guideline protocol was declared to have DTP.

\section{Statistical analysis}

Data was analyzed using Statistical Package for Social
Sciences (SPSS ${ }^{\circledR}$ statistics) program version 21 (SPSS; Chicago, IL, U.S.A). Binary logistic regression analysis was employed to identify determinants of drug related problems. To identify determinants of DTP, variables with $\mathrm{p}$-values $<0.05$ on a univariable/span $>$ logistic regression model were entered into a multivariable logistic regression model and variables with tailed p-value $<0.05$ were considered as statistically significant and were declared to be determinants of DTP.

\section{Results}

\section{Baseline characteristics of the participants}

A total of 241 adult hypertensive patients were enrolled and studied. The response rate was 100\%. From the total patients studied, $142(58.9 \%)$ participants were males. The average mean age of the participants was $45.11 \pm 11.79$ years with minimum peak age of 21 and maximum peak age of 73 years. Regarding age category of the patients, $69(28.6 \%)$ patients were in the ages of $45-54$ years, $57(23.7 \%)$ less than 35 years, $56(23.2 \%)$ between 35-44 years and 13(5.4\%) were 65 and above years. In addition, most, $197(81.7 \%)$ patients were married, $19(7.9 \%)$ widowed, $18(7.5 \%)$ single and $7(2.9 \%)$ divorced. Concerning level of education of the participants, most [137(56.8\%)] of the patients had no formal education, 65(27\%) were college and above, 24(10\%) complete elementary (1-8) school and 15(6.2\%) complete high school (9-12). Of all the participants, 126(52.3\%) were private workers, $56(23.2 \%)$ government employee, $41(17 \%)$ jobless, $12(5 \%)$ students, and 6(2.5\%) employed on non-governmental organizations.

\section{Antibypertensive medications}

Patients were prescribed one or two or three antihypertensive medicines. The average mean number of antihypertensive medicines prescribed for patients was $1.41 \pm 0.53$ ranging from 1-3 medications per patient. From the total participants studied, enalapril was the most commonly prescribed medication in most of the patients. It was prescribed for 148(61.5\%) patients and hydrochlorothiazide(HCT) was prescribed for $86(35.8 \%)$ patients (table $1)$. 
Table 1: Most frequently prescribed medications for HTN treatment at Ayder Comprehensive Specialized Hospital, March to June 2016

\begin{tabular}{|lcc|}
\hline Type of medication & Frequency & Percent \\
Enalapril & 148 & 61.5 \\
HCT & 86 & 35.8 \\
Nifedipine & 63 & 26.1 \\
Amilodipine & 36 & 15.0 \\
Atenolol & 4 & 1.6 \\
Propranolol & 4 & 1.6 \\
Methyldopa & 1 & 0.4 \\
\hline
\end{tabular}

HCT: Hydrochlorothiazide, HTN: Hypertension

Drug therapy problem and associated factors

A total of 357 DTPs were identified in 241 patients and the most common prevalent type of DTP identified was non adherence, which was identified in 143(40.1\%) patients. Among the patients, 134(55.6\%) had at least one identified DTP. From the patients having DTP, most $(n=76,56.7 \%)$ of the patients had one type of DTP and
53(39.6\%) patients had identified with two DTPs. Patients having uncontrolled blood pressure were more likely to have DTP as compared to patients who had controlled $\mathrm{BP}(\mathrm{COR}=0.567,95 \% \mathrm{CI}=0.332-0.967, \mathrm{p}=0.037)$. Therapeutic non-adherence was the most commonly identified DTP which was found to be identified in 143 (59.3\%) patients (table 2).

Table 2: DTP and types of DTPs identified at Ayder Comprehensive Specialized Hospital, March to June, 2016

\begin{tabular}{|llcc|}
\hline $\begin{array}{l}\text { Variables } \\
\text { Presence of DTP }\end{array}$ & $\begin{array}{c}\text { Number/patient } \\
\text { Patient }\end{array}$ & Percent(\%) \\
Yes & & 134 & \\
No & & 107 & 55.6 \\
Number of DTP & & Number & 44.4 \\
One & & 76 & \\
Two & & 53 & 56.7 \\
Three & & 4 & 39.6 \\
Four & & 1 & 3.0 \\
Total & & 134 & 7.0 \\
Type of DTP & Non-adherence & Number & 100.0 \\
Adherence & Needs additional drug therapy & 143 & \\
Indication & Unnecessary drug therapy & 61 & 40.1 \\
& Adverse drug event & 40 & 17.1 \\
Safety & Dose too high & 6 & 11.2 \\
& Dose too low & 60 & 1.7 \\
Effectiveness & Ineffective drug use & 44 & 0.8 \\
Total DTPs identified & & 357 & 16.8 \\
\hline
\end{tabular}

DTP: Drug therapy problem, DTPs: Drug therapy problems 
The respondents' adherence was found to be affected by different factors

We conducted bivariable logistic regression and Sub- stance use $(\mathrm{COR}=0.449,95 \% \mathrm{CI}: 0.231-0.87, \mathrm{p}=0.018)$ and comorbidity $(\mathrm{COR}=2.084,95 \% \mathrm{CI}: 1.192-3.65, \mathrm{p}=0.010)$ were significantly associated with DTP (table 3).

Table 3: Bivariable logistic regression analysis of variables associated with presence of drug therapy problem among adult hypertensive patients in ACSH, March to June, 2016.

\begin{tabular}{|c|c|c|c|}
\hline \multirow[t]{2}{*}{ Variable } & \multicolumn{2}{|c|}{ Drug therapy problem } & \multirow[t]{2}{*}{ COR (95\%CI), p-value } \\
\hline & No & Yes & \\
\hline \multicolumn{4}{|l|}{ Sex } \\
\hline Male & $61(43 \%)$ & $81(57 \%)$ & 1 \\
\hline Female & $42(42.4 \%)$ & $57(57.6 \%$ & $0.978(0.582-1.64) \mathrm{p}=0.934$ \\
\hline \multicolumn{4}{|l|}{ Age } \\
\hline$\leq 35$ year old & $28(49.1 \%)$ & $29(50.9 \%)$ & 1 \\
\hline $35-44$ & $23(40.4 \%)$ & $34(59.6 \%)$ & $1.43(0.68-2.99) \mathrm{p}=0.347$ \\
\hline $45-54$ & $32(46.4 \%)$ & $37(53.6)$ & $1.12(0.553-2.25) \mathrm{p}=0.759$ \\
\hline $55-64$ & $17(37 \%)$ & $29(63 \%)$ & $1.65(0.75-3.64) \mathrm{p}=0.217$ \\
\hline$\geq 65$ & $3(27 \%)$ & $9(75 \%)$ & $2.897(0.710-11.87) \mathrm{p}=0.138$ \\
\hline \multicolumn{4}{|l|}{ Marital status } \\
\hline Single & $8(44.4 \%)$ & $10(55.6 \%)$ & $0.989(0.374-2.611) \mathrm{p}=0.982$ \\
\hline Married & $87(44.2 \%)$ & $110(55.8 \%)$ & 1 \\
\hline Divorced & $2(28.6 \%)$ & $5(71.4 \%)$ & $1.977(0.375-10.44) \mathrm{p}=0.422$ \\
\hline Widowed & $6(31.6 \%)$ & $13(68.4 \%)$ & $1.71(0.63-4.69) p=0.295$ \\
\hline \multicolumn{4}{|l|}{ Residence } \\
\hline Urban & $59(41.8 \%)$ & $82(58.2 \%)$ & 1 \\
\hline Rural & $44(44 \%)$ & $56(56 \%)$ & $1.09(0.651-1.832) \mathrm{p}=0.739$ \\
\hline \multicolumn{4}{|l|}{ Education level } \\
\hline No formal & $56(40.9 \%)$ & $81(59.1 \%)$ & 1 \\
\hline Elementary $(1-8)$ & $12(50 \%)$ & $12(50 \%)$ & $0.691(0.29-1.65) \mathrm{p}=0.405$ \\
\hline High school (9-12) & $7(46.7 \%)$ & $8(53.3 \%)$ & $0.79(0.271-2.304) \mathrm{p}=0.666$ \\
\hline College and above & $28(43.1 \%)$ & $37(56.9 \%)$ & $0.914(0.503-1.66) \mathrm{p}=0.767$ \\
\hline \multicolumn{4}{|l|}{ Occupation } \\
\hline Employed & $27(43.5 \%)$ & $35(56.5 \%)$ & 1 \\
\hline Private worker & $58(46 \%)$ & $68(54 \%)$ & $0.904(0.490-1.67) \mathrm{p}=0.748$ \\
\hline Jobless & $18(34 \%)$ & $35(66 \%)$ & $1.5(0.703-3.207) \mathrm{p}=0.295$ \\
\hline \multicolumn{4}{|c|}{ Family history of hypertension } \\
\hline No & $72(42.9 \%)$ & $96(57.1 \%)$ & 1 \\
\hline Yes & $31(42.5 \%)$ & $42(57.5 \%)$ & $0.984(0.565-1.72) \mathrm{p}=0.955$ \\
\hline \multicolumn{4}{|c|}{ HTN duration in years } \\
\hline$\leq 5$ & $65(44.5 \%)$ & $81(55.5 \%)$ & 1 \\
\hline $6-10$ & $25(43.9 \%)$ & $32(56.1 \%)$ & $1.027(0.554-1.903) \mathrm{p}=0.932$ \\
\hline $11-15$ & $6(37.5 \%)$ & $10(62.5 \%)$ & $1.337(0.462-3.874) p=0.592$ \\
\hline $16-20$ & $7(31.8 \%)$ & $15(68.2 \%)$ & $1.72(0.662-4.467) p=0.266$ \\
\hline \multicolumn{4}{|l|}{ Salt intake } \\
\hline No & $45(45 \%)$ & $55(55 \%)$ & 1 \\
\hline Yes & $58(41.1 \%)$ & $83(58.9 \%)$ & $0.854(0.509-1.433) p=0.550$ \\
\hline \multicolumn{4}{|l|}{ Physical activity } \\
\hline Physically inactive & $101(43.7 \%)$ & $130(56.3 \%)$ & 1 \\
\hline Physically active & $2(20 \%)$ & $8(80 \%)$ & $0.322(0.067-1.55) \mathrm{p}=0.157$ \\
\hline \multicolumn{4}{|l|}{ Substance use } \\
\hline No & $88(46 \%)$ & $100(53.2 \%)$ & 1 \\
\hline Yes & $15(28.3 \%)$ & $38(71.7 \%)$ & $0.449(0.231-0.87) \mathrm{p}=0.018^{*}$ \\
\hline \multicolumn{4}{|c|}{ Mode of medication intake } \\
\hline Free & $34(37.8 \%)$ & $56(62.2 \%)$ & 1 \\
\hline Paid & $69(45.7 \%)$ & $82(54.3 \%)$ & $0.722(0.423-1.230) \mathrm{p}=0.230$ \\
\hline \multicolumn{4}{|c|}{ Number antihypertensive medication } \\
\hline Monotherapy & $57(38.8 \%)$ & $90(61.2 \%)$ & 1 \\
\hline$\geq$ two medications & $46(48.9 \%)$ & $48(51.1 \%)$ & $0.661(0.392-1.12) \mathrm{p}=0.121$ \\
\hline \multicolumn{4}{|l|}{ Comorbidity } \\
\hline No & $77(48.7 \%)$ & $81(51.3 \%)$ & 1 \\
\hline Yes & $26(31.3 \%)$ & $57(68.7 \%)$ & $2.084(1.192-3.65) \mathrm{p}=0.010^{*}$ \\
\hline
\end{tabular}

*: $\mathrm{p}$ value $<0.05,1$ : Reference, COR: Crude odds ratio, CI: Confidence interval 
Multivariable logistic regression was employed to identify the predictors of drug therapy problem. The analysis model explains $52.3 \%(\mathrm{R} 2=0.523, \mathrm{p}=0.002)$ of the DTP variability of the response data confined around its mean. Two variables (substance use and comorbidity) were significantly associated with DTP in the bivariable logistic regression and after we conducted multivariable logistic regression, substance use $(\mathrm{AOR}=0.445,95 \% \mathrm{CI}=$
0.227-0.870, $\mathrm{p}=0.018)$ and comorbidity $(\mathrm{AOR}=2.099$, $95 \% \mathrm{CI}=1.192-3.694, \mathrm{p}=0.010)$ were found to be the predictors of DTP. Patients who reported substance use were less likely to have DTP than patients who did not use substance. Moreover, patients who had evidence of comorbidity were 2 times more likely to have DTP than patients who did not have evidence of comorbidity (table 4).

Table 4: Multivariable logistic regression analysis of variables associated with presence of drug therapy problem among adult hypertensive patients in ACSH, March to June, 2016.

\begin{tabular}{|lllll|}
\hline Variable & Drug therapy problem & COR (95\%CI)p-value & AOR(95\%CI), p-value \\
& No & Yes & & \\
& & & & \\
Substance use & & & & 1 \\
No & $88(46 \%)$ & $100(53.2 \%)$ & 1 & $0.445(0.227-0.870) \mathrm{p}=0.018^{*}$ \\
Yes & $15(28.3 \%)$ & $38(71.7 \%)$ & $0.449(0.231-0.87) \mathrm{p}=0.018^{*}$ & \\
Comorbidity & & & & 1 \\
No & $77(48.7 \%)$ & $81(51.3 \%)$ & 1 & \\
Yes & $26(31.3 \%)$ & $57(68.7 \%)$ & $2.084(1.192-3.65) \mathrm{p}=0.010^{*}$ & $2.099(1.192-3.694) \mathrm{p}=0.010^{*}$ \\
\hline
\end{tabular}

*: p value $<0.05,1$ : Reference, COR: crude odds ratio, AOR: Adjusted odds ratio, CI: Confidence interval

\section{Discussion}

The prevalence of DTP identified in this study was accounted to be $55.6 \%$. This is not consistent with the study done in Felege Hiwot Referral Hospital, South west Ethiopia. There were 357 numbers of DTPs, on the other hand, a less number of DTPs (105) was found in the study done in Felege Hiwot referral Hospital. ${ }^{24,25}$ This might be due to the fact that the study in Felege Hiwot Referral Hospital enrolled and studied small number of medical patients. The mean number of DTP was $1.48 \pm$ 0.597 which is comparable with the findings reported in Jimma which was $1.8 \pm 0.8 .^{25}$

The most common DTP identified was non-adherence which was identified in $143(59.3 \%)$ of the patients. This result is consistent with the study conducted in Southern Kivu province of the Democratic Republic Congo and Ghana. ${ }^{26,27}$ However, this was incongruent with the study done in Mexico which found a non-adherence prevalence of $42.8 \% .{ }^{28}$ A study conducted in Southern Kivu of DRC showed that $86.4 \%$ of hypertensive patients were non-adherence which is not in lined with this study. ${ }^{20}$ This difference may be due to uncertainty or lack of knowledge about the aim or function of the drug, economic is- sue and long duration of therapy. The result in this study found DTP which was dose too high $(1.2 \%)$ which is not in line with the result of research done in China which was $(19.1 \%){ }^{29}$ This difference may be due to frequent administration of the antihypertensive medications.

Adverse drug events were occurred in $1.7 \%$ of the patients studied. This is not in line with research done in Sweden and in India which showed a prevalence of adverse drug event to be $25.7 \%$ and $10 \%$ respectively. ${ }^{30,31}$ This may be because of difference in patient knowledge on which drug is the cause for adverse effect occurred, poor documentation and poor habit of adverse drug event report by patients.

Of the total type of DTPs, $11.2 \%$ was unnecessary drug therapy. This is not in line with findings from India which reported a prevalence of unnecessary drug therapy to be $16.7 \%$. Moreover, dose related problems (25.9\%) followed by need for additional drugs (25\%) in this study are not in line with the study done in India which were $35.1 \%$ and $19.7 \%$ respectively. ${ }^{25,32}$ A study conducted in South America, Brazil on the existence of DTPs showed that $44 \%$ was dosage too low which is not in line with this study which found dosage too low to be $16.8 \%{ }^{33}$ 
A study conducted in China regarding drug related problems found that, $24.1 \%$ were ineffective indication which is not in line with this study which described a prevalence of ineffective indication to be $12.3 \% .^{29}$ This may be because of prescribing errors. In this study we also found that substance use and comorbidity were the predictors of DTP.

This study has some flaws and limitations. First because some data were collected through interview there might be recall bias especially during antihypertensive medication adherence status assessment. Second the effect of DTP on outcome of hypertension was not studied. Thirdly the identified DTPs were not intervened. Fourth some six seriously ill patients were excluded from the study thus this might affect the finding of the study.

\section{Conclusion}

More than half of the patients studied had identified with at least one DTP. Non-adherence to antihypertensive medications was the most commonly identified DTP. Thus efforts that boost antihypertensive compliance should be adopted to solve drug related problem of hypertensive patients.

\section{List of abbreviations}

ACSH: Ayder Comprhensive Specialized Hospital

AMI: Acute Myocardial Infarction

AOR: Adjusted Odds Ratio

BP: Blood Pressure

CHD: Congestive Heart Disease

CHF: Congestive Heart Failure

CI: Confidence Interval

COR: Crude Odds Ratio

DBP: Diastolic Blood Pressure

DTP: Drug Therapy Problem

DTPs: Drug Therapy Problems

HCT: Hydrochlorothiazide

HTN: Hypertension

JNC-8: Eighth Joint National Committee

PVD: Peripheral Vascular Disease

SBP: Systolic Blood Pressure

SPSS: Stastical Package for Social Science

\section{Declarations}

\section{Ethical approval and consent to participate}

The study was approved by the Institutional Review Board of College of Health Sciences, Mekelle Universi- ty. Permission was also offered from ACSH to conduct the study. Informed oral consent was obtained from all patients.

\section{Consent to publish}

Not applicable.

\section{Availability of data and materials}

All relevant data are within the paper and its supporting information files.

\section{Disclosure statement}

The authors declare that they have to competing interest to disclose.

\section{Funding}

The authors received no specific funding for this work.

\section{Authors' contributions}

All authors contributed toward data analysis, drafting and revising the paper and agree to be accountable for all aspects of the work.

\section{Authors' information}

SW, YL, TD and TM are a clinical pharmacists and lecturers at MekelleUniversity. TF is an assistant lecturer at Mekelle University. GW is a pharmacist.

\section{Acknowledgements}

We would like to acknowledge the study participants and data collectors. We would also like to acknowledge Mekelle University for allowing us conduct the study. Our deepest gratitude also goes to Ayder Comprehensive Specialized Hospital staff that helped us in collecting data.

\section{References}

1. Weber MA, Schiffrin EL, White WB, Mann S, Lindholm LH, Kenerson JG, et al. Clinical Practice Guidelines for the Management of Hypertension in the Community. A Statement by the American Society of Hypertension and the International Society of Hypertension. 2014;16(1).

2. Dennison-himmelfarb C, Handler J, Lackland DT. Evidence-Based Guideline for the Management of High Blood Pressure in Adults. Report From the Panel Members Appointed to the Eighth Joint National Committee (JNC 8). 2014;1097(5):507-20.

3. Mufunda J, Mebrahtu G, Usman A, Nyarango P, Kosia 
A, Ghebrat Y, et al. The prevalence of hypertension and its relationship with obesity : results from a national blood pressure survey in Eritrea. J Hum Hypertens. 2006;20:5965 PubMed.

4. Guessous I, Bochud M, Theler J, Gaspoz J, Peche A. 1999 - 2009 Trends in Prevalence, Unawareness, Treatment and Control of Hypertension in Geneva. PLoS One. 2012;7(6).

5. Reddy KS, Naik N PD. Hypertension in the developing world a consequence of progress. Curr Cardiol Rep. 2006;8(6):399 PubMed -404.

6. VO Omuemu, OH Okojie CO. Blood pressure pattern and prevalence of hypertension in a rural community in Edo State. J Med Biomed Res. 2006;5(2).

7. Falase AO, Stewart S, Sliwa K. Blood pressure, prevalence of hypertension and hypertension related complications in Nigerian Africans: A review. 2012;4(12):327-40. PubMed

8. Ali ZH, Taha NM. Effect of nursing guideline for recently diagnosed hypertensive patients on their knowledge, self-care practice and expected clinical outcomes. $J$ Nurs Educ Pract. 2015;5(3):1 PubMed -11.

9. Hareri HA, Gedefaw M, Simeng B. Assessment of prevalence and associated factors of adherence to antihypertensive agents among adults on follow up in Adama Referal hospital East Shoa, Ethiopia-cross sectional study. 2014;3(1):760-70.

10. Bonsa F, Gudina EK, Hajito KW. Prevalence of hypertension and associated factors in bedele town, southwest ethiopia. EthiopJ Heal Sci. 2014;24(6):21 PubMed -6. 11. Lecture S, Chobanian A V, Smithwick R. The Hypertension Paradox-More Uncontrolled Disease despite Improved Therapy. The New EnglJ of Med. 2009;361:878-87. 12. Helelo TP, Gelaw YA, Adane AA. Prevalence and Associated Factors of Hypertension among Adults in Durame Town, Southern Ethiopia. PLoS One. 2014;9(11):1 PubMed -9.

13. Tesfaye F, Byass P, Wall S. Population based prevalence of high blood pressure among adults in Addis Ababa : uncovering a silent epidemic. BMC Cardiovasc Disord. 2009;9(39):1-9.

14. Getahun W, Gedif T, Tesfaye F. Regular Khat ( Catha edulis ) chewing is associated with elevated diastolic blood pressure among adults in Butajira, Ethiopia: A comparative study. 2010;4-11.

15. Misganaw A, Mariam DH, Ali A, Araya T. Epidemiol- ogy of Major Non-communicable Diseases in Ethiopia: A Systematic Review. J Health Popul Nutr. 2014;32(1):1-13. 16. Egan BM, Zhao Y, Axon RN, Brzezinski WA, Ferdinand KC. Uncontrolled and Apparent Treatment Resistant Hypertension in the United States, 1988 to 2008. Circulation. 2011;124(9):1046-58.

17. Knight EL, Bohn RL, Wang PS, Glynn RJ, Mogun $\mathrm{H}$, Avorn J. Predictors of Uncontrolled Hypertension in Ambulatory Patients. Hypertension. 2001;38(4):809-14.

18. Esposti ED, Martino M Di, Sturani A, Russo P, Dradi C, Falcinelli S, et al. Risk factors for uncontrolled hypertension in Italy.J Hum Hypertens. 2004;18:207-13. PubMed 19. Mallat SG, Samra SA, Younes F, Sawaya M. Identifying predictors of blood pressure control in the Lebanese population-a national, multicentric survey - I-PREDICT. BMC Public Health. 2014;14(11):1-9. PubMed

20. Youssef RM, Moubarak II. Patterns and determinants of treatment compliance among hypertensive patients. East Mediterr Health J. 2005; 8: 45 PubMed

21. Omuemu, VO, Okojie, OH Omuemu CE. Blood pressure pattern and prevalence of hypertension in a rural community in Edo State. J Biomed Sci. 2006; 5 (2): 79 -86. PubMed

22. J. Cipolle RJ, Stran LM and Morley PC. pharmaceutical care practices: the clinician's Guide, $2^{\text {nd }}$ Edition. Minnocitta.

23. James PA, Oparil S, Carter BL, et al. 2014 Evidence-based guideline for the management of high blood pressure in adults: Report from the panel members appointed to the Eighth Joint National Committee (JNC 8). JAMA 2014; DOI:10.1001/jama.2013.284427. Available at: http://jama.jamanetwork.com/article.aspx?articleid=1791497

24. Rashed Al Bannay, Aysha Husain MB. Blood Pressure Control and Predictors of Uncontrolled Hypertension. Babrain Med Bull. 2014;36(3).

25. Goverwa TP, Masuka N, Tshimanga M, Gombe NT, Takundwa L, Bangure D, et al. Uncontrolled hypertension among hypertensive patients on treatment in Lupane District, Zimbabwe, 2012. BMC Res Notes [Internet]. 2014 Jan;7(1):703. Availablefrom:http://www.pubmedcentral. nih.gov/articlerender.fcgi?artid=4197296\&tool=pmcentrez\&rendertype $=$ abstract

26. Tesfaye A, Kumela K, Wolde M. Blood Pressure Control Associates and Antihypertensive Pharmacotherapy Patterns in Tikur Anbessa General Specialized Hospital 
Chronic Care Department, Addis Ababa, Ethiopia. Am J Biomed Life Sci. 2015;3(3):41-8.

27. Franklin SS, Jacobs MJ, Wong ND, L'Italien GJ, Lapuerta P: Predominance of Isolated systolic hypertension among middle -aged and elderly US hypertensives : analysis based on National Health and Nutrition Examination Survey (NHANES) III. Hypertension. 2001; 37:869-874 PubMed .

28. Zhang M, Meng Y, Yang Y, Liu Y, Dong C, Xiao J, et al. Major inducing factors of hypertensive complications and the interventions required to reduce their prevalence : an epidemiological study of hypertension in a rural population in China. BMC Public Health. 2011;11(1):301 PubMed . Available from: http://www.biomedcentral. com/1471-2458/11/301

29. Dehghan M, Nayeri ND, Iranmanesh S. Validating the Persian Version of the Hill-Bone's Scale of
"Compliance to High Blood Pressure Therapy". Br J Med Med Res. 2011;5(2): 235-46. PubMed

30. Ramli A, Ahmad NS, Paraidathathu T. Medication adherence among hypertensive patients of primary health clinics in Malaysia. Patient Prefer Adherence .2012; 6: 613622.

31. Mandavi, D'Cruz S, Sachdev A, Tiwari P (2012) Adverse drug reactions \& their risk factors among Indian ambulatory elderly patients. Indian J Med Res. 136: 404410.

32. Nascimento Y, Carvalho WS, Acurcio FA. Drug related problems observed in a pharmaceutical careservice, Belo Horizonte, Brazil. Brazilian Journal of Pharmacentical Sciences. 2009; 45(2):322-422.

33. Asch SM, Mcglynn EA, Hiatt L, Adams J, Hicks J, Decristofaro A, et al. Quality of care for hypertension in the United States. BMC Cardiovasc Disord. 5(1):1-9. 